\title{
Adsorption of Orotic Acid on Ag Colloidal Nanoparticles
}

\author{
Luisa ANDRONIE ${ }^{1)}$, Vioara MIRESAN*1), Ioana POP ${ }^{2)}$, Camelia RADUCU ${ }^{19}$, \\ Aurelia COROIAN ${ }^{1)}$, Cristi COROIAN ${ }^{1)}$, Daniel COCAN ${ }^{1)}$, Radu CONSTANTINESCU ${ }^{1)}$ \\ 1)University of Agricultural Sciences and Veterinary Medicine, Faculty of Animal Science \\ and Biotechnologies, 3-5 Mănăştur Street, 400372 Cluj-Napoca, Romania \\ ${ }^{2)}$ University of Agricultural Sciences and Veterinary Medicine, Faculty of Horticulture, \\ 3-5 Mănăștur Street, 400372 Cluj-Napoca, Romania \\ *Corresponding author, email: vmiresan@yahoo.com \\ Bulletin UASVM Animal Science and Biotechnologies 72(1) / 2015 \\ Print ISSN 1843-5262; Electronic ISSN 1843-536X \\ DOI:10.15835/buasvmcn-asb:10794
}

\begin{abstract}
The Raman spectra of polycrystalline anhydrous orotic acid have been also recorded and compared to the SERS data. These form are found to chemisorb on Ag colloidal nanoparticles exhibiting different SERS spectral pattern. SERS of orotic acid analysis suggested a titled geometry orientation with respect to the surface. Different adsorption behavior of these molecular species is discussed in the present study based on the Raman and SERS vibrational analysis of the related species.
\end{abstract}

Keywords: Orotic Acid, Micro-Raman, SERS

\section{INTRODUCTION}

Orotic acid (OA, 1,2,3,6-tetrahydro-2,6-dioxo4-pyrimidinecarboxylic acid) is a heterocyclic compound with the formula $\mathrm{C}_{5} \mathrm{H}_{4} \mathrm{~N}_{2} \mathrm{O}_{4}$. It is also known as pyrimidinecarboxylic acid and B13, that salts play an important role in biological systems as precursors of pyrimidine nucleotide and are found in cells and body fluids of many living organisms, these compounds are applied in medicine as biostimulators of the ionic exchange processes in organisms. There is also a great interest for orotic acid in relation to food protection and nourishment research (Akalin et al., 1996; Ruasmadiedo et al., 1996; Kumberger et al., 1991). The biological imerent metalportance of orotic acid is well known since it is the only effective precursor of the biosynthesis of pyrimidine bases. The chemistry and biochemistry of this molecule, as will as those with different metal complexes, have been intensively investigated.

\section{AIMS AND OBJECTIVES}

The aim of this work is to investigate the adsorption ability of the orotic acid and its deuterated species on Ag colloidal nanoparticles. Surface plasmon resonance of the Ag colloidal nanoparticles was employed for the investigation of the adsorbed geometry and the functional groups involved in adsorption on the nanostructured Ag surface.

\section{MATERIALS AND METHODS}

Micro-Raman and SERS spectra were collected using a Raman microspectrometer (Horiba Jobin Yvon, model LabRam), equipped with 1800 grooves/mm holographic gratings. For the excitation, the $632.8 \mathrm{~nm}$ lines from a He$\mathrm{Ne}$ laser or the $785 \mathrm{~nm}$ line from a diode laser was employed. The spectra were collected in the backscattering geometry using a microscope equipped with an Olympus LMPlanFL 50x or 


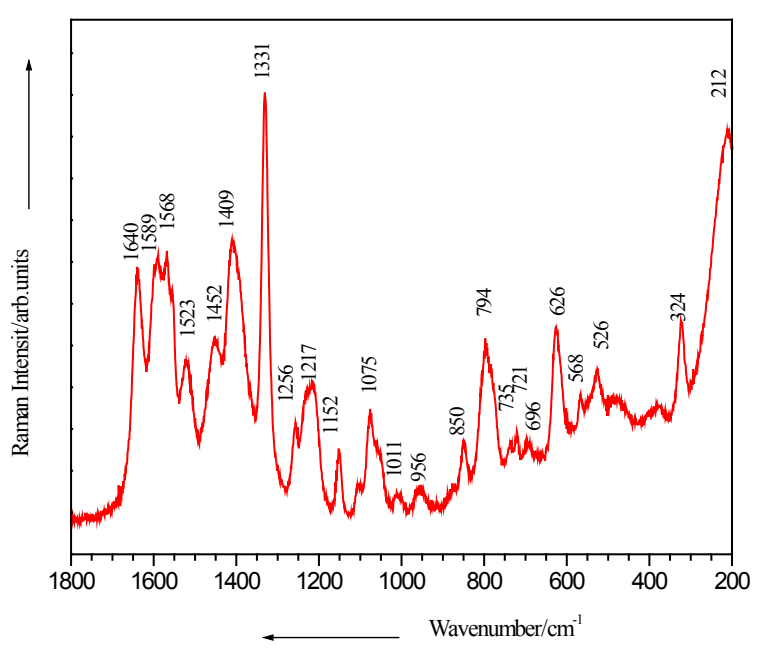

a)

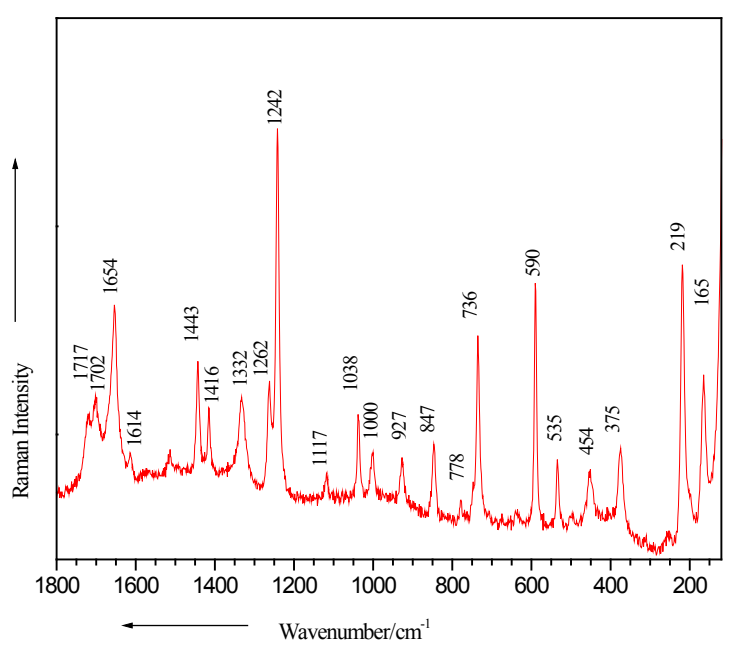

b)

Fig. 1. Raman (a) and SERS (b) spectra of orotic acid, Excitation $632.8 \mathrm{~nm}$

10x objective with a spectral resolution of $2 \mathrm{~cm}$ ${ }^{1}$. The spectrally dispersed Raman signal was detected with a Peltier-cooled CCD camera, with 16 bits dynamic range, size $1024 \times 256$ pixel. The spectral data were analyzed using the LabSpec 4.08 software. The Surface-enhanced Raman scattering of orotic acid adsorbed on Ag colloidal particles have been obtained dropped into $3 \mathrm{ml}$ sodium citrate-reduces silver colloids (Lee, 1982) resulting a final concentration of $10^{-4} \mathrm{moll}^{-1}$ and the vibrational bands have been investigated in the spectral range of $180-1700 \mathrm{~nm}$.

\section{RESULTS AND DISCUSSION}

Showing at Figure 1a, large differences well as similarities in the band positions and relative intensities are observed on passing from Raman to SERS spectra.

In other study the IR and Raman spectra of polycrystalline anhydrous orotic acid and its $\mathrm{N} 1, \mathrm{~N} 3$, and 012 trideuterated isotopomer was recorded in the $4000-40 \mathrm{~cm}^{-1}$ spectral interval and the vibrational analyses of nucleosides, nucleotides are discussed (Hernanz, 2000; Lee et al., 1982). The surface-enhanced Raman spectra (SERS) of orotic acid were obtained using citratereduced silver colloids at $10^{-4} \mathrm{~mol}^{-1}$ concentration. The forms are found to chemisorb on Ag colloidal nanoparticles exhibiting different SERS spectral pattern. SERS of orotic acid has also been reported and it was found to a titled geometry orientation with respect to the surface (Fig. 1b). Different adsorption behavior of these molecular species is discussed in the present study based on the Raman and SERS vibrational analysis.

\section{CONCLUSION}

SERS spectra of orotic acid adsorbed on Ag colloidal particles have being obtained and analyzed in conjunction to the vibrational Raman data. Orotic acid $\mathrm{NaOH}$ solution have been also recorded and used for reliable interpretation of the SERS spectra. The $-\mathrm{COOH}$ or -COOD groups were found to contribute to the adsorption on the Ag nanoparticles. A strong chemisorption of both species with respect to the Ag surface has been concluded.

\section{REFERENCES}

1. Akalin AS, S Gone (1996). Sci. Int. 51 (554).

2. Ruasmadiedo P, JC Badagancedo, EG Fernandez, DG Dellano, CG Delos, Reyes Gavilan (1996). Preservation of the microbiological and biochemical quality of raw milk by carbon dioxide addition: A pilot-scale study, J. Food Prot. 59:502-508.

3. Kumberger O, J Riedo, H Smidbaur (1991). Chem. Ber. 124 (2739).

4. Lee PC, Meisel DJ (1982). Adsorption and surfaceenhanced Raman of dyes on silver and gold sols, J.Phys. Chem. 86 (17): 3391-3395.

5. Hernanz A, F Billes, I Bratu, R Navarro (2000). Vibrational analysis and spectra of orotic acid, Biopolymer, 57(3): 187-98. 